\title{
Substance use disorders and sexually transmitted infections: a public health perspective
}

\author{
Vijaya Murali \& Sabitha Jayaraman
}

\begin{abstract}
Summary
It has long been recognised that substance use disorders and sexually transmitted infections (STIs) are common comorbid conditions. It is clear that treating one condition while leaving the other leads to increased morbidity and mortality in this patient population. However, engaging patients in treatment is extremely challenging, which is a huge public health concern. This article focuses on various sexually transmitted infections seen in the substance misuse population and means of primary, secondary and tertiary prevention.
\end{abstract}

\section{Declaration of interest}

None.

\section{Learning objectives}

- Be aware of the current extent of comorbidity between substance use disorders and STIs

- Learn about primary, secondary and tertiary prevention of STIs in people with substance use disorders

- Understand the links between high-risk sexual behaviour and illicit drug use, as shown by current evidence

It has been argued that the substance misuse population is at high risk of sexually transmitted infections (STIs) -diseases that can be transmitted by unprotected sex. As not all STIs are symptomatic, individuals may be unaware that they have an infection but they are still able to pass it on to any sexual partner. In recent years, there has been increasing interest in improving outcomes for this population and in integrating STI screening and treatment into substance misuse treatment programmes.

\section{Prevalence of comorbid substance misuse and STIs}

Individuals with substance use disorders are at increased risk for acquiring and transmitting STIs through blood-borne exposure and sexual activity. There is evidence supporting the close association between drug use and having an STI (DeHovitz 1994; Diaz 1994; Cleghorn 1995), and several studies have reported that substance misusers are at higher risk of infection (Marx 1991; Radcliffe 2001). There are numerous common factors involved in the higher risk of STIs in the substance misuse population: these include social deprivation, poor access to healthcare, delays in seeking healthcare and an increased number of casual sexual partners. Drug misuse may be an important surrogate marker for other demographic characteristics associated with increased risk of STIs, such as Black ethnicity, social deprivation and young age (Low 2001).

The highest rates of STIs among people with serious mental illness appear in those who also meet the criteria for substance use disorders (3646\%) (Klinkenberg 2003).

Chen et al (2007) concluded that, in people with borderline personality disorder, occurrence of STIs is generally higher among those with comorbid substance use disorders. High rates of STIs were also noted in individuals with a dual diagnosis of bipolar disorder and substance misuse (Meade 2005).

The prevalence of life-time substance use is substantially higher among men who have sex with men than among heterosexual men and women. In the UK, the highest prevalences of HIV are among men who have sex with men (47 per 1000) and men and women from Black African communities (38 per 1000) (National Institute for Health and Care Excellence 2014). Public Health England identified three distinct but overlapping areas in which men who have sex with men bear a burden of ill health: sexual health and HIV; mental health; and the use of drugs, alcohol and tobacco (Public Health England 2014a).

The prevalence of HIV in this group of men who have sex with men has increased in recent years to $6.3 \%(6 / 96)$ in 2016; this compares with $5.0 \%$ (44/885) over the period 2006 to 2015. This probably reflects the emergence of injecting drug use among some groups of (often HIV positive) men who have sex with men (MSM) who take drugs around or during sex. In Unlinked Anonymous Monitoring Survey (UAM) MSM were more often
Vijaya Murali is a consultant psychiatrist with Birmingham and Solihull Mental Health NHS Foundation Trust. Sabitha Jayaraman is speciality doctor lead with the Kidderminster Integrated Sexual Health Service.

Correspondence Dr Vijaya Murali, Longbridge Health and Community Centre, Parkway, Rednal, B45 9PL. Email: vijaya.murali1@nhs.net

\section{Copyright and usage} (C) The Royal College of Psychiatrists 2018 
recent initiates to injecting, and a greater proportion injected mephedrone and ketamine, 2 drugs associated with 'slamming' - that is, the injection of drugs before or during planned sexual activity to sustain, enhance, disinhibit or facilitate sex (56). MSM were more likely to report needle/syringe sharing than heterosexual men, and were more likely to have $10+$ sexual partners. The data suggest that 'slamming' is evident among MSM accessing general drug services, which could negatively impact the UK's low HIV prevalence among PWID. Hepatitis C remains the most common blood-borne infection among people who inject drugs (PWID), and there are significant levels of transmission among this group in the UK. Injecting risk behaviours have declined but remain a problem and changing patterns of psychoactive drug injection remain a concern (Public Health England 2016).

Injecting drug use continues to be the most important risk factor for infection with the hepatitis C virus (HCV) in the UK. Data from the Unlinked Anonymous Monitoring survey of people who inject drugs suggest that levels of infection in this group remained high in 2012 (49\% in England, $34 \%$ in Northern Ireland and 33\% in Wales); in 2011-2012, 53\% of injecting drug users surveyed in Scotland tested positive for antibodies to hepatitis (Public Health England 2014b).

\section{Sexual behaviour and substance misuse}

The likelihood of high-risk sexual behaviour in individuals with substance use disorders increases with comorbid Axis I disorders (Shoptaw 2003). Ross et al (2000) emphasised the importance of considering triple diagnoses of drug dependence, mental disorder and STIs in substance misusers, as they have a high prevalence of STIs as well as a history of buying or selling sex for money or drugs. Drugs can facilitate high-risk sexual behaviours through their physiological and psychological properties, and van Empelen et al (2003) reported that most drug users practice unprotected sex and have little motivation to begin preventive measures such as using condoms.

\section{Crack cocaine}

The drug most commonly associated with STIs is smokable free-base (crack) cocaine. Crack cocaine use is associated with hypersexuality, impeded male orgasm and the 'sex for drugs' trade. Users also engage in high-risk sexual behaviours such as multiple sexual partners, repeated forceful sex and fellatio performed by individuals who have bad oral hygiene and damaged oral and buccal mucosa resulting from the heat of crack pipes (Elwood
1997). Among male crack users there is an increased rate of trading crack for sex, particularly with other males, whereas female crack users tend to trade sex for crack.

There is a specific association between low-dose cocaine and decreased inhibition and increased sexual desire, which lead to an increasing number of partners and reduced use of condoms (Gawin 1998). However, chronic use of cocaine can impair sexual function and reduce interest in sex (Cregler 1986).

\section{Alcohol}

Alcohol is a prominent risk factor in the transmission of STIs as it can impair sexual decisionmaking and disturb the immune system; it is also associated with multiple sexual partners and unprotected sex (Shuper 2010). High-risk sexual behaviour combined with excess alcohol use may also result in a rapid disease progression. Excess alcohol use can also cause rapid progression of blood-borne viral diseases in infected individuals, which might be attributed to impaired sexual function seen with increased alcohol intake (Ross 2006).

\section{Methamphetamine}

Methamphetamine is inexpensive and has a long half-life that enables long sexual episodes. An emerging risk is its use by men who have sex with men. Methamphetamine appears to be associated with new HIV infections and the promotion of multidrug-resistant HIV, and there appears to be a direct association between the level of methamphetamine use and prevalence of HIV infection (Shoptaw 2006).

Methamphetamine use induces euphoria, brightens mood, eliminates fatigue, decreases appetite, focuses attention and, for many, heightens libido (Shoptaw 2007). The drug's disinhibitory effect facilitates high-risk sexual behaviour, but there is little understanding of the direct effects of methamphetamine on HIV transmission. Methamphetamine dries the mucosa and reduces the sensitivity of the rectal and genital area, which might encourage longer and rougher sexual episodes, contributing to increased likelihood of bruising and tearing in the region and greater opportunities for transmission of infectious disease.

\section{Young people}

Drug-involved juvenile offenders have a high rate of STIs resulting from first intercourse at an early age, unprotected sex, multiple partners, more permissive attitudes about sex and low self-efficacy in practising safe sex (Marvel 2009). 


\section{Management of comorbid STIs and substance use disorders}

The substance misuse population is clearly at high risk of STIs and this is increasingly becoming a public health hazard. Many surveys show that deaths are due to preventable high-risk sexual behaviour and exposure to STIs. In managing STIs there are three levels of prevention: primary, secondary and tertiary.

\section{Primary prevention}

Management of STIs in substance misusers starts with primary prevention. Primary prevention strategies emphasise general health promotion, riskfactor reduction and other health-protective measures. They include public health education, the promotion of individual responsibility for health through health education, advice on safer sexual behaviours, programmes aimed at fostering healthier lifestyles, and immunisation against bloodborne viruses such as hepatitis B (Centers for Disease Control 2012). The British HIV Association (BHIVA) with the British Association for Sexual Health and HIV (BASHH) recommend Pre-exposure prophylaxis for HIV prevention (PrEP) as an effective intervention tool. Therefore $\mathrm{BASHH}$ and BHIVA strongly recommend that PrEP be made available within a comprehensive HIV prevention package to:

- MSM, trans men and trans women who are engaging in condomless anal sex

- HIV-negative partners who are in serodifferent heterosexual and same-sex relationships with a HIV-positive partner whose viral replication is not suppressed

- Other heterosexuals considered to be at high risk. (BHIVA-BASHH 2016)

The main aim is to prevent the onset of STIs by reducing the individual's risk of acquiring them. There is evidence for the effectiveness of public health interventions. One meta-analysis (Althoff 2015) concluded that behavioural interventions targeted at preventing STIs in Latina women in the USA successfully reduced risky sexual behaviour and incident STIs. The protective effects were shown to persist for as long as 2 years following the intervention.

Sexually transmitted infections and drug misuse are integral parts of a single problem and treatment of one should be accompanied by screening and treatment of the other. There is a need for STI screening and treatment among the substance misuse population. Likewise, there is a need for substance misuse screening in sexual health clinics. Every patient seeking treatment for substance misuse should have access to a healthcare professional trained in sexual health and have a clear pathway to a local specialist genito-urinary medicine service. A risk assessment for STIs and blood-borne viruses should be carried out for all such patients. Those at high risk who test positive should have access to appropriate treatment.

Training and awareness programmes on sexual health and blood-borne viruses should be provided to all healthcare professionals to promote stigma reduction. Effective means of preventing infection from injecting drugs and protective devices for safer sex (e.g. condoms and dental dams) should be available and accessible to all high-risk populations such as substance misusers, as should an accelerated course of hepatitis B vaccination to prevent transmission.

Integrated prevention services that address both STIs and substance use disorders should be promoted and introduced in settings where staff interact with or manage individuals who use illicit drugs, such as prisons, needle exchange programmes, juvenile detention centres and community substance misuse teams. Not all substance misusers are at equal risk of STIs, but an integrated prevention service will increase access to treatment, improve its timeliness, and increase the effectiveness of efforts to prevent STIs that share common risk factors, behaviours and social determinants.

Interventions that reduce poverty, increase jobs with health insurance, create access to substance misuse treatment, and reduce the availability of crack cocaine in communities may have an impact on the HIV epidemic.

The high rate of STIs among juvenile drug offenders should make it a public health priority to address the unmet needs of these young people, who require integrated family-based prevention programmes (Marvel 2009).

\section{Secondary prevention}

If a person has already acquired an STI, then secondary prevention should come into force. Secondary prevention focuses on early detection and rapid intervention, such as treatment or health promotion. Its purpose is to cure disease, slow its progression, or reduce its impact on individuals or communities. It should be noted that routine screening for STIs is likely to detect disease at an early stage, when intervention may be more cost-effective. As STIs are a public health concern, it is important to implement public screening programmes as well as screening in clinical settings such as sexual health and substance misuse clinics.

As already mentioned, alcohol use accelerates progression of blood-borne viral diseases such as 
HIV and hepatitis B and C. Brief interventions to modify alcohol use should be carried out in public health and primary care settings, both to improve the individual's health and because they are likely to reduce risky sexual behaviour (Bertholet 2005; Schmiege 2009). Interventions such as motivational interviewing to address substance misuse, risky sexual behaviour and non-adherence to anti-retroviral therapy are successful. A recent literature review (Dillard 2017) shows strong evidence that motivational interviewing alone or in conjunction with other strategies can change the health behaviour of people living with HIV. Improvements were recorded in various domains, including sexual behaviour, adherence to antiretroviral therapy, substance misuse and mental health; however, no improvements in viral load or CD4 T-cell count were seen. Motivational interviewing is a flexible tool that can be used by clinicians and other practitioners across different healthcare settings.
Good evidence now exists to suggest that the combination of effective drug treatments, such as opioid substitution therapy, support for safe injecting, for example through needle exchange programmes, and treatment of HCV infection in people who inject drugs, can reduce the incidence and prevalence of HCV infection (Vickerman 2014). Needle exchange programme are provided in the UK through pharmacies and specialist services.

Post-exposure prophylaxis for HIV (PEPSE) plays a crucial role in secondary prevention of STIs. Pathogenesis indicates that there may be a window of opportunity to abort HIV infection by inhibition of viral replication. Administration of anti-retroviral drugs within $72 \mathrm{~h}$ of high-risk exposure can reduce the risk of acquiring HIV. The British Association for Sexual Heath and HIV recommends that PEPSE is initiated when the estimated risk is 1 in 1000 or greater. Both those who misuse drugs and healthcare professionals involved in their care should be made aware of PEPSE. There should be

TABLE 1 Examples of primary, secondary and tertiary prevention of sexually transmitted infections (STIs) and blood-borne viruses in individuals and populations with substance use disorders

\begin{tabular}{|c|c|c|c|c|}
\hline \multirow[t]{2}{*}{ Disease } & \multirow{2}{*}{$\begin{array}{l}\text { Level of } \\
\text { intervention }\end{array}$} & \multicolumn{3}{|c|}{ Level of prevention } \\
\hline & & Primary & Secondary & Tertiary \\
\hline \multirow[t]{2}{*}{ STIS } & Individual & $\begin{array}{l}\text { Counselling on safe sex practices; } \\
\text { needle exchange programmes; } \\
\text { alcohol and drug use screening } \\
\text { and brief interventions }\end{array}$ & $\begin{array}{l}\text { Screening for STIs in } \\
\text { various settings }\end{array}$ & $\begin{array}{l}\text { Ongoing follow-up to identify } \\
\text { recurrence of infection }\end{array}$ \\
\hline & Population & $\begin{array}{l}\text { Public campaigns alerting people to } \\
\text { the benefits of safe sex } \\
\text { practices, promoting safe } \\
\text { injecting techniques; helping } \\
\text { people access substance } \\
\text { misuse programmes }\end{array}$ & $\begin{array}{l}\text { Organised STI } \\
\text { screening } \\
\text { programmes }\end{array}$ & $\begin{array}{l}\text { Implementation of health services } \\
\text { organisational models that } \\
\text { improve access to high- } \\
\text { quality integrated care }\end{array}$ \\
\hline \multirow[t]{2}{*}{ Hepatitis C } & Individual & $\begin{array}{l}\text { Counselling on safe drug use to } \\
\text { prevent HCV transmission; } \\
\text { counselling on safer sex; opioid } \\
\text { substitution therapy }\end{array}$ & $\begin{array}{l}\text { Screening for HCV } \\
\text { infection in } \\
\text { patients with a } \\
\text { history of } \\
\text { injecting drug use }\end{array}$ & $\begin{array}{l}\text { HCV therapy to cure infection and } \\
\text { prevent transmission }\end{array}$ \\
\hline & Population & $\begin{array}{l}\text { HCV prevention includes safer sex } \\
\text { practices, programmes to } \\
\text { discourage needle sharing } \\
\text { among intravenous drug users }\end{array}$ & $\begin{array}{l}\text { Establishing a } \\
\text { universal testing } \\
\text { system for HCV } \\
\text { in high-risk } \\
\text { groups }\end{array}$ & $\begin{array}{l}\text { Similar to primary prevention; } \\
\text { ensuring close control of high- } \\
\text { risk sites such as tattoo } \\
\text { parlours that have been } \\
\text { associated with outbreaks }\end{array}$ \\
\hline \multirow[t]{2}{*}{ Hepatitis B } & Individual & $\begin{array}{l}\text { Counselling on safe drug use to } \\
\text { prevent hepatitis B } \\
\text { transmission; counselling on } \\
\text { safer safe; opioid substitution } \\
\text { therapy; immunisation }\end{array}$ & $\begin{array}{l}\text { Screening for hepatitis } \\
\text { B in patients with } \\
\text { a history of } \\
\text { injecting drug use }\end{array}$ & $\begin{array}{l}\text { Referral to hepatologist for } \\
\text { ongoing monitoring }\end{array}$ \\
\hline & Population & $\begin{array}{l}\text { Hepatitis B prevention includes } \\
\text { safer sex practices, } \\
\text { programmes to discourage } \\
\text { needle sharing among } \\
\text { intravenous drug users }\end{array}$ & $\begin{array}{l}\text { Establishing a } \\
\text { universal testing } \\
\text { system for } \\
\text { hepatitis B in } \\
\text { high-risk groups }\end{array}$ & $\begin{array}{l}\text { Ensuring close control of high-risk } \\
\text { sites such as tattoo parlours } \\
\text { that have been associated } \\
\text { with outbreaks }\end{array}$ \\
\hline \multirow[t]{2}{*}{ HIV } & Individual & Post-exposure prophylaxis & Screening for HIV & Referral to HIV clinics \\
\hline & Population & $\begin{array}{l}\text { Raising awareness through HIV } \\
\text { prevention programmes }\end{array}$ & $\begin{array}{l}\text { Establishing HIV } \\
\text { screening in high- } \\
\text { risk groups }\end{array}$ & $\begin{array}{l}\text { Improving quality of life through } \\
\text { provision of necessary } \\
\text { services to people with HIV }\end{array}$ \\
\hline
\end{tabular}

HCV, hepatitis C virus. 
a clear referral pathway and individuals should be appropriately directed. As $24 \mathrm{~h}$ access is essential, PEPSE should be available in accident and emergency departments; other places of access would include genito-urinary medicine clinics and sexual assault referral centres (Cresswell 2016).

\section{Tertiary prevention}

Tertiary prevention aims to reduce the impact caused by the disease on the patient's function, longevity and quality of life through active rehabilitation. Strategies that involve both therapeutic and rehabilitative measures once disease is firmly established make up tertiary prevention. These include modifying risk behaviour, ensuring regular health check-ups, and environmental modifications and rehabilitation to help the individual to accommodate to disability and thus enhance quality of life. Treatment of HIV and hepatitis C form part of tertiary prevention, as they aim to improve quality of life through provision of necessary services.

\section{Conclusions}

It is clear that people with substance use disorders are at higher risk of STIs, although there is paucity of data about the type of drug use and type of sexual behaviour most implicated. Awareness of the comorbidity of substance use disorders and STIs, routine screening for disease and appropriate management, in both sexual health and substance misuse settings, are likely to improve outcome. A combination of primary, secondary and tertiary interventions (Table 1 ) is needed to achieve a meaningful degree of prevention and protection against STIs in the substance misuse population.

\section{References}

Althoff MD, Grayson CT, Witt L, et al (2015) A meta-analysis of the efficacy of behavioral interventions to reduce risky sexual behavior and decrease sexually transmitted infections in Latinas living in the United States. Health Education \& Behavior, 42: 709-18.

Bertholet N, Daeppen JB, Wietlisbach V, et al (2005) Reduction of alcohol consumption by brief alcohol intervention in primary care: systematic review and meta-analysis. Archives of Internal Medicine, 165: 986-95.

British HIV Association and BASHH (2016) BHIVA-BASHH Position Statement on PrEP in UK, Second Update May 2016. BHIVA-BASHH.

Centers for Disease Control (2012) Integrated Prevention Services for HIV Infection, Viral Hepatitis, Sexually Transmitted Diseases, and Tuberculosis for persons who use drugs illicitly: Summary Guidance from Centers for Disease Control and Prevention and the U.S. Department of Health and Human Services. CDC Recommendations and Reports, 61(5).

Chen EY, Brown MZ, Lo TY, et al (2007) Sexually transmitted disease rates and high-risk sexual behaviors in borderline personality disorder versus borderline personality disorder with substance use disorder. Journal of Nervous and Mental Disease, 195: 125-9.

Cleghorn FR, Jack N, Murphy JR, et al (1995) HIV-1 prevalence and risk factors among sexually transmitted disease clinic attenders in Trinidad. AIDS, 9: 389-94.
Cregler LL, Mark H (1986) Medical complications of cocaine abuse. New England Journal of Medicine, 315: 1495-500.

Cresswell F, Walters L, Briggs $E$, et al (2016) UK guideline for the use of HIV post-exposure prophylaxis following sexual exposure, 2015. International Journal of STD \& AIDS, 27: 713-38.

DeHovitz JA, Kelly P, Feldman J, et al (1994) Sexually transmitted diseases, sexual behaviour, and cocaine use in inner city women. American Journal of Epidemiology, 140: 1125-34.

Diaz T, Chu SY, Conti L, et al (1994) Risk behaviors with persons with heterosexually acquired HIV infection in the United States: results of a multicentre surveillance project. Journal of Acquired Immune Deficiency Syndrome, 7: 958-63.

Dillard PK, Zuniga JA, Holstad MM (2017) An integrative review of the efficacy of motivational interviewing in HIV management. Patient Education and Counseling, 100: 636-46.

Elwood WN, Williams MS, Bell DC, et al (1997) Powerlessness and HIV prevention among people who trade sex for drugs ("strawberries"). AIDS Care, 9: 273-84.

Gawin FH, Ellinwood EH (1998) Cocaine and other stimulants actions, abuse, and treatment. New England Journal of Medicine, 318: 1173-82.

Klinkenberg WD, Caslyn RJ, Morse GA, et al (2003) Prevalence of human immunodeficiency virus, hepatitis $B$, and hepatitis $C$ among homeless persons with co-occurring severe mental illness and substance use disorders. Comprehensive Psychiatry, 44: 293-302.

Low N, Sterne JA, Barlow D (2001) Inequalities in rates of gonorrhoea and chlamydia between black ethnic groups in Southeast London: cross sectional study. Sexually Transmitted Infections, 77: 15-20.

Marvel F, Rowe CL, Colon-Perez L, et al (2009) Multidimensional family therapy HIV/STD risk-reduction intervention: an integrative family-based model for drug-involved juvenile offenders. Family Process, 48: 71-84.

Marx R, Aral SO, Rolfs RT, et al (1991) Crack, sex, and STD. Sexually Transmitted Diseases, 18: 92-101.

Meade CS, Sikkema KJ (2005) HIV risk behaviour among adults with severe mental illness: Asystematic review. Clinical Psychology Review, 25: $433-457$.

National Institute for Health and Care Excellence (2014) HIV Testing (Local Government Briefing LGB21). NICE (nice.org.uk/guidance/lgb21).

Public Health England (2014a) Promoting the Health and Wellbeing of Gay, Bisexual and Other Men Who Have Sex with Men: Initial Findings. PHE.

Public Health England (2014b) Hepatitis C in the UK: 2014 Report. PHE.

Public Health England (2016) Shooting Up: Infections among people who inject drugs in the UK, update November 201. PHE.

Radcliffe KW, Ahmad S, Gilleran G, et al (2001) Demographic and behavioural profile of adults infected with chlamydia: a case-control study. Sexually Transmitted Infections, 77: 265-70.

Ross MW, Hwang LY, Leonard L, et al (2000) Sexual behaviour, STDs and drug use in a crack house population. International Journal of STD \& AIDS, 10: 224-30

Ross JD, Radcliffe KW (2006) Why do those using illicit drugs have higher rates of sexually transmitted infection? International Journal of STD \& AIDS, 17: 247-53.

Schmiege SJ, Broaddus MR, Levin M, et al (2009) Randomized trial of group interventions to reduce HIV/STD risk and change theoretical mediators among detained adolescents. Journal of Consulting and Clinical Psychology, 77: 38-50

Shoptaw S, Peck J, Reback CJ, et al (2003) Psychiatric and substance dependence comorbidities, sexually transmitted diseases, and risk behaviors among methamphetamine-dependent gay and bisexual men seeking outpatient drug abuse treatment. Journal of Psychoactive Drugs, 35(suppl 1): $161-8$.

Shoptaw S, Reback CJ (2006) Associations between methamphetamine use and HIV among men who have sex with men: a model for guiding public policy. Journal of Urban Health, 83: 1151-7.
MCO answers

1 b 2 c 3 c 4 d 5 e 
Shoptaw S, Reback CJ (2007) Methamphetamine use and infectious disease-related behaviors in men who have sex with men: implications for interventions. Addiction, 102(suppl 1): 130-5.

Shuper PA, Neuman M, Kanteres F, et al (2010) Casual considerations on alcohol and HIV/AIDS - a systematic review. Alcohol and Alcoholism, 45: 159-66. van Empelen P, Kok G, Hoebe CJPH, et al (2003) A qualitative study of factors that influence the motivation-action relationship in condom use among drug users. Health Education, 103: 230-9.

Vickerman P, Page K, Maher L, et al (2014) Opiate substitution treatment and HCV prevention: Building an evidence base? Addiction 109: 20602061

\section{MCOs}

Select the single best option for each question stem

1 Which of the following mental illnesses is associated with the highest rates of sexually transmitted infections?

a Borderline personality disorder

b Substance use disorder

c Schizophrenia

d Bipolar affective disorder

e Attention-deficit hyperactivity disorder.

2 Which of the following factors has been associated with increased risk of sexually transmitted infections in the substance misuse population in the UK?

a Caucasian ethnicity

b Old age

c Black ethnicity

d Higher socioeconomic status

e Female gender.
3 Which illicit drug is most commonly associated with sexually transmitted infections? a Heroin

b Methamphetamine

c Cocaine

d Cannabis

e Amphetamine.

4 Which of the following is not a primary prevention of sexually transmitted infection in substance misuse?

a Screening

b Immunisation

c Use of condoms

d Treatment of HIV

e Needle exchange programmes.
5 Which of the following sexual behaviours is least likely to be associated with increased risk of sexually transmitted infection in people with substance use disorder?

a Multiple sexual partners

b Repeated forceful sex

c Fellatio performed by individuals who have bad oral hygiene and damaged oral and buccal mucosa

d Unprotected sex

e A heterosexual relationship. 